Original Article

\title{
Immediate effects of dynamic sitting exercise on the lower back mobility of sedentary young adults
}

\author{
Uraiwan Chatchawan $^{1)^{*}}$, Unthika JupamatangB ${ }^{2)}$, Sunisa Chanchitc ${ }^{3)}$, \\ Rungthip Puntumetakul ${ }^{1)}$, Wanida Donpunha ${ }^{1)}$, Junichiro Yamauchi ${ }^{1,4,5)}$ \\ 1) Research Center in Back, Neck, Other Joint Pain and Human Performance (BNOJPH), Faculty of \\ Associated Medical Sciences, Khon Kaen University: Mitraphab Highway, Muang District, Khon \\ Kaen 40002, Thailand \\ 2) Kutchap Hospital, Thailand \\ 3) Pan Beauty Care Clinic, Thailand \\ 4) Graduate School of Human Health Sciences, Tokyo Metropolitan University, Japan \\ 5) Future Institute for Sport Sciences, Japan
}

\begin{abstract}
Purpose] The aim of this study was to investigate the effects of dynamic sitting exercises during prolonged sitting on the lower back mobility of sedentary young adults. [Subjects and Methods] Seventy-one subjects aged between 18-25 years participated in this study. Following a randomized crossover study design, subjects were randomly assigned to two groups: sitting only and dynamic sitting exercise. The dynamic sitting exercise was a combination of lower back hyperextension and abdominal drawing-in movements which were repeated 6 times in a 1-minute period and performed every 20 minutes during a 2-hour sitting session. Lumbar range of movement was measured with the modified-modified Schober test, and the pain intensity was evaluated using the visual analog scale. [Results] After the experiment, the lumbar range of movement was significantly impaired in the sitting only group; however, it was significantly improved in the dynamic sitting exercise group. There were significant differences in lumbar range of movement of both flexion and extension between the groups. No significant difference in pain intensity between the groups was found. [Conclusion] These results suggest that dynamic sitting exercises during prolonged sitting can prevent decreases in lumbar range of movement in both back flexion and extension following a 2-hour sitting period.

Key words: Back exercise, Flexibility, Long sitting
\end{abstract}

(This article was submitted Jun. 23, 2015, and was accepted Jul. 31, 2015)

\section{INTRODUCTION}

Low back pain (LBP) is a worldwide health problem and a major cause of disability in the general population ${ }^{1-3)}$. Causes of LBP are combinations of many factors including improper posture, overloading of the back, immobility, and trunk muscle weakness ${ }^{4-7}$. One of the primary causes of back pain is a sitting posture sustained over long periods ${ }^{5,8)}$. Many sedentary workers keep a markedly curved back posture with low muscle activity during sitting ${ }^{9}$. This habitual improper posture as well as low muscle activity of the back may weaken lumbar muscle strength ${ }^{10)}$, because the total amount of muscle activity in daily life affects both muscle volume and strength. When the daily requirements on muscle activity are decreased, the muscle becomes smaller and weaker ${ }^{11)}$. Additionally, improper posture while sitting in a chair burdens the low back with an unnecessary load

\section{*Corresponding author. Uraiwan Chatchawan (E-mail:} pomuraiwan67@gmail.com)

(C2015 The Society of Physical Therapy Science. Published by IPEC Inc. This is an open-access article distributed under the terms of the Creative Commons Attribution Non-Commercial No Derivatives (by-ncnd) License $<$ http://creativecommons.org/licenses/by-nc-nd/3.0/> . due to spinal alignment. These prolonged sitting-induced decreases in muscle strength and function can increase the prevalence of LBP. Accordingly, a proper sitting posture is an important ergonomic factor in the prevention of LBP. Exercise programs are an important treatment and a form of rehabilitation for $\mathrm{LBP}^{12-15)}$. These exercise programs are effective at decreasing pain, improving physical function, and increasing oxygenation and blood flow to the lower back of individuals with $\mathrm{LBP}^{16-18)}$. Exercises performed while sitting could provide therapeutic effects for preventing decreases in the lumbar range of movement (LROM) and reduce LBP; however, there is a lack of information concerning the effects of exercise on the lower back during prolonged sitting conditions. Therefore, the aim of the present study was to investigate the effects of dynamic sitting exercises during prolonged sitting on the lower back mobility of sedentary young adults. Dynamic exercise also represents an important instrument for assuming a proper posture under spinal loading conditions during sitting. Moreover, it can provide useful information to advance our understanding of LBP, which, in turn, may provide new approaches towards preventing LBP during periods of long-term sitting. The hypothesis tested in this study was that the frequency of muscle activation is a key factor in maintaining a healthy low back condition, and that exercise during sitting can prevent a decrease in low 
back mobility.

\section{SUBJECTS AND METHODS}

Eighty healthy young subjects were recruited from the general community using bulletin boards and verbal requests addressed to persons living in the city of Khon Khaen. All the subjects received a physical screening performed by a physical therapist and a physician. The inclusion criteria of the physical screening were physical activity without regular participation in exercise training, no history of previous LBP within the six months prior to the study, and no pain on the experimental day. The exclusion criteria were: a history of back, hip joint and lower limb surgeries; congenital deformity of the spine or limbs; or musculoskeletal problems including tuberculosis, scoliosis, ankylosing spondylitis, spondylolisthesis and rheumatoid arthritis. A randomized crossover study was conducted according to the flowchart design displayed in Fig. 1. After the physical screening, 74 subjects meeting the inclusion criteria were randomly assigned to one of two groups: the sitting only CON group, or the dynamic sitting exercise (DSE) group. This was followed by a one day washout period, after which a crossover assignment was performed for each subject with a member of the other group using simple randomization (random number). After the first day of baseline assessments, 3 subjects dropped out leaving a total of 71 healthy young males $(\mathrm{n}=46)$ and females $(\mathrm{n}=$ 25), 18 to 25 years of age (age: $21.0 \pm 2.0$ years; height: 1.64 $\pm 0.08 \mathrm{~m}$; mass: $55.23 \pm 7.48 \mathrm{~kg}$; body mass index (BMI): $20.50 \pm 1.81 \mathrm{~kg} / \mathrm{m}^{2}$; mean $\pm \mathrm{SD}$ ), who completed the study. All subjects were informed about the experimental procedures as well as the purpose of the study prior to the onset of the study. Written informed consent was obtained from each participant. The protocol and informed consent forms were approved by the Khon Kaen University Ethics Committee for Human Research.

The DSE was modified from the chair-care decompression exercises ${ }^{19}$. It was a combination of lower back hyperextension and abdominal drawing-in exercises. Participants were instructed to perform the following sequence of actions: 1) relax their arms on the armrests, 2) extend the lower back until they could feel slight stretching in the lower back and hold for $5 \mathrm{sec}$, then 3) gently draw in abdomen to return to the neutral sitting posture in $1-5 \mathrm{sec}$. This exercise was performed six times in a 1-minute period and repeated every 20 minutes while sitting and watching a classic movie over a 2-hour period. Prior to the experiment, each participant was given and explanation and demonstration of how to perform each step of the DSE by a licensed physical therapist with 1 year of experience. The participants in CON were instructed to watch the same movie over a 2-hour period. This group received treatments at a different time from the DSE to make sure that they did not know which treatment group they were in by observing the other group. In addition, prior to the experiment all the participants were asked to go to the restroom and perform their ablutions, as they were not allowed to leave the chair during the experimental period. The assessments of each group were performed before and after each intervention.

The outcome measures included LROM and pain levels,

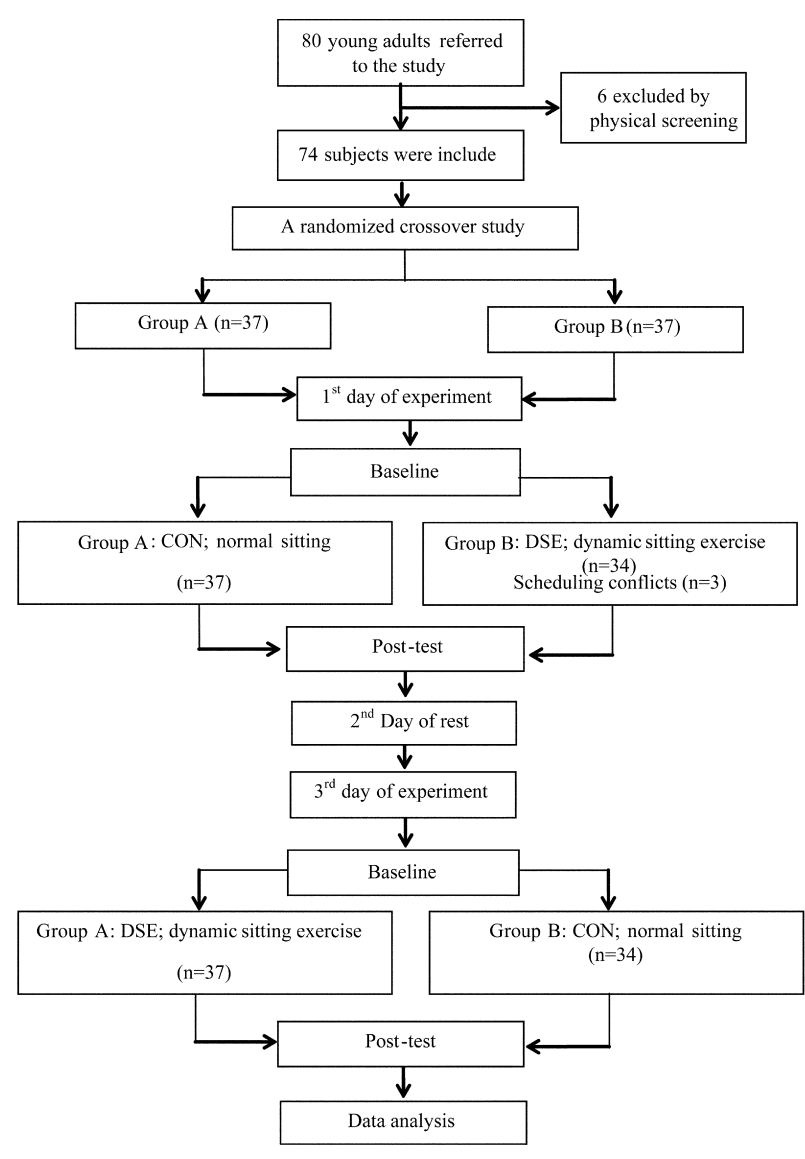

Fig. 1. Flow chart of the study design

which were measured with the modified-modified Schober test (MMST) and the visual analog scale (VAS), respectively. They were assessed by a physical therapist who was blinded to the treatment group of each participant. The MMST was used to measure ROM in both lumbar flexion and extension ${ }^{20)}$. As shown in Fig. 2, the first landmark (X) was marked at the spinal intersection of the left and right posterior superior iliac spines, and the second landmark (Y) was $15 \mathrm{~cm}$ above the $\mathrm{X}$. The LROM for flexion and extension were assessed as the distance between two points. An increased flexion distance and a decreased extension distance indicated a better LROM. These measurements were taken three times and the mean value was used for further analysis. Before conducting the main study, the inter- and intra-rater reliabilities of back flexion and extension measurements were determined using 10 healthy subjects who did not participate in the main study. The inter-rater reliability was tested by assessment of the intra-class correlation coefficient (ICC) using a two way mixed effect model (3:1), and comparing the performance of the physical therapist with that of an expert physical therapist with 20 years of experience. Then, the intra-rater reliability was assessed using the physical therapist.

The VAS is a common assessment of pain intensity in clinical and research settings. The VAS is rated by a subject on a scale drawn on a 10 -cm-long line, with 0 indicating no pain and 10 indicating intolerable pain. Subjects were asked to make a mark on the line commensurate with their 
perceived levels of pain intensity ${ }^{21)}$

All data are presented as means $\pm \mathrm{SD}$. The inter and intra-rater reliabilities of back flexion and extension measurements were assessed using the intra-class correlation coefficient (ICC) and a two way mixed effect model (3:1). The LROM and pain levels were normally distributed according to the Shapiro-Wilk W test. To examine whether
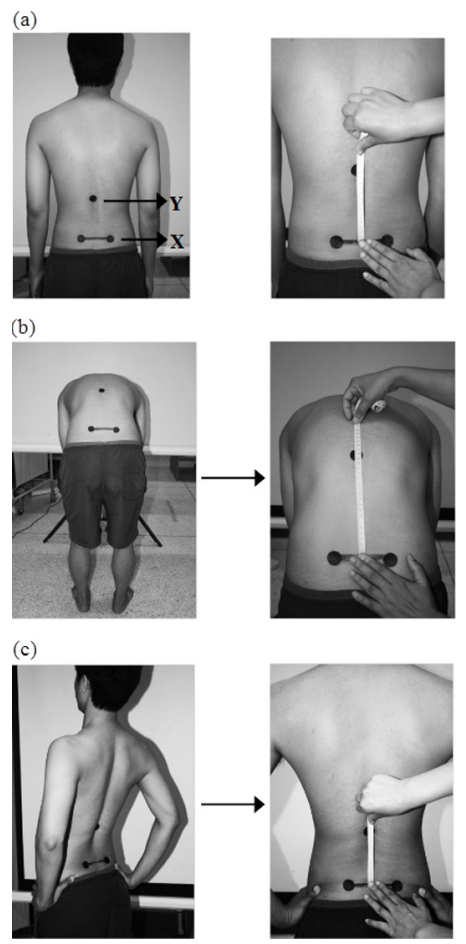

Fig. 2. Modified-modified Schober test

Landmarks (a): X represents the spinal intersection of a horizontal line between the left and right posterior superior iliac spines, and $\mathrm{Y}$ is the point $15 \mathrm{~cm}$ above $\mathrm{X}$. Measurements of flexion (b) and extension (c). there was any carryover effect from the order of treatment due to the 2-period crossover design, a repeated-measures ANOVA was performed. When there was no evidence of a carryover effect, the independent t-test or Mann Whitney $\mathrm{U}$ test were used to compare the relative changes (pre- and post-intervention) between the two treatment groups. Statistical significance was accepted for values of $p<0.05$.

\section{RESULTS}

The ICCs (3:1 model) of the intra-reliability of back flexion were 0.99 (95\% CI: 0.99 to 1.00$)$ for both the 1 st and 2nd researcher, and for back extension 0.96 (95\% CI: 0.89 to 0.99 ) for the 1 st researcher and 0.86 ( $95 \% \mathrm{CI}: 0.63$ to 0.96$)$ for the 2 nd researcher. The ICC (3:1 model) of the inter-rater reliability of back flexion and extension were 1.0 (95\% CI: 0.99 to 1.00$)$ and 0.98 (95\% CI: 0.93 to 0.99$)$, respectively. The intra-rater reliability and inter-rater-reliability between the two researchers for the measurements of lower back flexion and extension were not significantly different $(\mathrm{p}>$ $0.0001)$.

In the examination of the carryover effects from the baseline of the first of the experiment to the third day of the experiment in the two groups, no significant intra-group differences were found (Table 1). The data derived from combining the two-experimental sessions were used for the main analysis. After the 2-hour sitting period, LROM of both flexion and extension had improved in the DSE group and was impaired in the CON group. For the DSE group, LROMs of back flexion at pre- and post-test were $20.56 \pm$ $1.42 \mathrm{~cm}$ and $20.84 \pm 1.47 \mathrm{~cm}$, respectively $(\mathrm{p}<0.0001)$, and LROMs of back extension were $12.65 \pm 0.87 \mathrm{~cm}$ and 12.40 $\pm 1.91 \mathrm{~cm}$, respectively $(\mathrm{p}<0.0001)$. For the CON group, pre- and post-testing of LROMs of back flexion were 20.62 \pm 1.38 and $20.41 \pm 1.38 \mathrm{~cm}$, respectively $(\mathrm{p}<0.005)$, and LROMs of back extension were $12.45 \pm 0.75$ and $12.76 \pm$ $0.76 \mathrm{~cm}$, respectively $(\mathrm{p}<0.0001)$. LROMs of both flexion and extension were significantly greater in the DSE group

Table 1. Lower back mobility and pain after 2 hours of sitting

\begin{tabular}{lcccccccc}
\hline & \multicolumn{3}{c}{ 1st day: session I (CON-DSE) } & \multicolumn{3}{c}{ 3rd day: session II (DSE-CON) } \\
\cline { 2 - 9 } & \multicolumn{2}{c}{ CON $(\mathrm{n}=37)$} & \multicolumn{2}{c}{ DSE $(\mathrm{n}=37)$} & DSE $(\mathrm{n}=34)$ & \multicolumn{2}{c}{ CON $(\mathrm{n}=34)$} \\
\cline { 2 - 9 } & Pre & Post & Pre & Post & Pre & Post & Pre & Post \\
\hline Flexion $(\mathrm{cm})$ & $20.81 \pm 1.45$ & $20.60 \pm 1.5$ & $20.53 \pm 1.49$ & $20.83 \pm 1.61$ & $20.59 \pm 1.37$ & $20.85 \pm 1.32$ & $20.41 \pm 1.30$ & $20.19 \pm 1.23$ \\
Extension (cm) & $12.60 \pm 0.82$ & $12.89 \pm 0.84$ & $12.71 \pm 1.0$ & $12.40 \pm 1.04$ & $12.59 \pm 0.73$ & $12.41 \pm 0.75$ & $12.30 \pm 0.64$ & $12.62 \pm 0.64$ \\
Pain levels* & 0 & $1.41 \pm 1.96$ & 0 & $1.54 \pm 2.06$ & 0 & $1.44 \pm 1.94$ & 0 & $1.12 \pm 1.79$ \\
\hline
\end{tabular}

Values are presented as the mean \pm SD. + indicates increase of range of motion in extension at post-test. * indicates the score on the visual analog scale (VAS).

Table 2. Relative changes in lower back mobility and pain after 2 hours of sitting

\begin{tabular}{lcccc}
\hline & CON & DSE & Mean difference & $95 \%$ CI \\
\hline Flexion $(\mathrm{cm})$ & $-0.21 \pm 0.56$ & $0.28 \pm 0.36^{\#}$ & 0.49 & 0.33 to 0.65 \\
Extension $(\mathrm{cm})$ & $0.31 \pm 0.45$ & $-0.25 \pm 0.51^{\#}$ & -0.55 & -0.71 to -0.40 \\
Pain levels* & $1.27 \pm 1.87$ & $1.50 \pm 2.0$ & 0.23 & -0.42 to 0.87 \\
\hline
\end{tabular}

Values are presented as the mean \pm SD. ${ }^{*}$ indicates score on the visual analog scale (VAS). ${ }^{*}$ indicates significantly different $(\mathrm{p}<0.001)$ from CON. 
than in the CON group (Table $2 ; \mathrm{p}<0.001$ ). According to the inclusion criteria, none of the participants reported pain before sitting in both sessions. After sitting, subjects in the DSE group reported a slightly higher increase in pain intensity than those in the CON group. However, no significant difference between the two groups was found (Table 1). After sitting, the combination data of both the DSE and CON groups reported increased pain intensity, as assessed by VAS, $1.27 \pm 1.87 \mathrm{~cm}$ and $1.50 \pm 2.0 \mathrm{~cm}$, respectively; but, there was no significant difference between the two groups (Table 2).

\section{DISCUSSION}

This study provides unprecedented evidence indicating that dynamic sitting exercises during prolonged sitting periods can maintain lower back mobility of both flexion and extension as measured by the modified-modified Schober test. Because a decrease in lower back flexibility is one of the major causes of lower back problems, dynamic sitting exercises during prolonged sitting may be an important technique for preventing low back problems in healthy young adults. Although it is important to note that not all LBP arises from back inflexibility, the results of this study suggest that exercise during sitting can maintain low back mobility and the frequency of muscle activation is a key factor in the maintenance of a healthy low back condition.

Prolonged sitting has been shown to be associated with various back problems. Previous studies have shown that sitting in a chair without lumbar support for a 2-hour period causes LBP, stiffness, fatigue, and buttocks numbness ${ }^{22)}$. Sitting in a standard office chair for 30 minutes produced an increase in lumbar flattening and a decrease in thoracolumbar curvature ${ }^{23)}$. The results of the present study could also demonstrate that prolonged sitting resulted in an impairment of LROM, which might be a cause of LBP. On the other hand, dynamic sitting exercises performed during the 2-hour sitting period prevented the loss of low back mobility. Similarly, sitting on an exercise ball, as compared with sitting on an office chair, elicited greater improvement in trunk, lumbar, and spine mobility ${ }^{24}$. Sitting on a dynamic chair increases spinal length because the passive motion of this type of chair provides spinal distress relief; however, sitting on a static chair decreases the spinal length ${ }^{25)}$. Various exercises have elicited positive effects in patients with LBP and lumbar instability. Lumbar flexibility exercises performed for two weeks elicited improvements in lumbar ROM and decreases in the LBP symptoms of patients with non-specific $\mathrm{LBP}^{26}$ ). Our previous study demonstrated that a 10 -week core stabilization exercise program reduced functional disability and pain intensity while improving deep abdominal muscle activation in subjects with clinical lumbar instability $^{14)}$. The combination of exercise, massage therapy, and lumbar support is an effective treatment and provides the tools needed to release muscle stiffness, decrease pain, and improve physical functions ${ }^{15,27,28)}$. Stretching and core stability exercises also have beneficial effects on muscle relaxation and spinal alignment ${ }^{29}$, and can help prevent LBP. The mechanism of lower back hyperextension and abdominal drawing-in exercises in dynamic sitting exercises may increase the extensibility of the non-contractile capsular and ligamentous tissues around the spine, thereby enhancing spinal mobility and improving LROM. In addition, enhancement of the spinal height may be explained by the similar effect of "off-loading posture" using chair-care decompression exercises ${ }^{19)}$.

The study was conducted using a cross-over design which allowed control of individual confounding factors. The LROM assessment was performed blinded and the measurements of LROM were found to have very high degrees of reliability. Since this study examined healthy adults aged between 18-25 years only, the derived results may not be generalizable to other age groups. Furthermore, it was not feasible for the participants to be blinded to their treatment group due to the nature of the intervention and the study design. Despite these limitations, our findings may contribute to the advancement of the general understanding of LBP caused by periods of long-term sitting.

In conclusion, dynamic sitting exercises were performed during a 2-hour sitting session and improved lumbar mobility, whereas prolonged sitting without exercise decreased lumbar mobility. These results indicate that dynamic sitting exercises may provide an effective intervention for the impairment of lower back flexibility caused by prolonged sitting, a condition afflicting many office workers. Future studies are needed to determine the clinical efficacy of dynamic sitting exercises either over the long term or in patients with LBP.

\section{ACKNOWLEDGMENTS}

The authors would like to thank the volunteer subjects who participated in this study. This study was supported by the Research Center in of Back, Neck, Other Joint Pain and Human Performance (BNOJPH), Faculty of Associated Medical Sciences, Khon Kaen University, Khon Kaen, Thailand.

\section{REFERENCES}

1) Freburger JK, Holmes GM, Agans RP, et al.: The rising prevalence of chronic low back pain. Arch Intern Med, 2009, 169: 251-258. [Medline] [CrossRef]

2) Hoy D, Brooks P, Blyth F, et al.: The epidemiology of low back pain. Best Pract Res Clin Rheumatol, 2010, 24: 769-781. [Medline] [CrossRef]

3) Hoy D, Bain C, Williams G, et al.: A systematic review of the global prevalence of low back pain. Arthritis Rheum, 2012, 64: 2028-2037. [Medline] [CrossRef]

4) Shiri R, Karppinen J, Leino-Arjas P, et al.: The association between obesity and low back pain: a meta-analysis. Am J Epidemiol, 2010, 171: 135 154. [Medline] [CrossRef]

5) Roffey DM, Wai EK, Bishop P, et al.: Causal assessment of awkward occupational postures and low back pain: results of a systematic review. Spine J, 2010, 10: 89-99. [Medline] [CrossRef]

6) de Schepper EI, Damen J, van Meurs JB, et al.: The association between lumbar disc degeneration and low back pain: the influence of age, gender, and individual radiographic features. Spine, 2010, 35: 531-536. [Medline] [CrossRef]

7) Keawduangdee P, Puntumetakul R, Swangnetr M, et al.: Prevalence of low back pain and associated factors among farmers during the rice transplanting process. J Phys Ther Sci, 2015, 27: 2239-2245. [Medline] [CrossRef]

8) Yildirim Y, Gunay S, Karadibak D: Identifying factors associated with low back pain among employees working at a package producing industry. J Back Musculoskeletal Rehabil, 2014, 27: 25-32. [Medline] 
9) Mork PJ, Westgaard RH: Back posture and low back muscle activity in female computer workers: a field study. Clin Biomech (Bristol, Avon), 2009, 24: 169-175. [Medline] [CrossRef]

10) O'Sullivan PB, Mitchell T, Bulich P, et al.: The relationship beween posture and back muscle endurance in industrial workers with flexion-related low back pain. Man Ther, 2006, 11: 264-271. [Medline] [CrossRef]

11) Yamauchi J, Kurihara T, Yoshikawa M, et al.: Specific characterization of regional storage fat in upper and lower limbs of young healthy adults. Springerplus, 2015, 4: 402. [Medline] [CrossRef]

12) van Middelkoop M, Rubinstein SM, Verhagen AP, et al.: Exercise therapy for chronic nonspecific low-back pain. Best Pract Res Clin Rheumatol, 2010, 24: 193-204. [Medline] [CrossRef]

13) Wajswelner H, Metcalf $B$, Bennell $K$ : Clinical pilates versus general exercise for chronic low back pain: randomized trial. Med Sci Sports Exerc, 2012, 44: 1197-1205. [Medline] [CrossRef]

14) Areeudomwong P, Puntumetakul R, Jirarattanaphochai K, et al.: Core stabilization exercise improve pain intensity, function disability and trunk muscle activity of patients with lumbar instability: a pilote randomized controlled study. J Phys Ther Sci, 2012, 24: 1007-1012. [CrossRef]

15) Peungsuwan P, Sermcheep P, Harnmontree P, et al.: The effectiveness of Thai exercise with traditional massage on the pain, walking ability and QOL of older people with knee osteoarthritis: a randomized controlled trial in the Community. J Phys Ther Sci, 2014, 26: 139-144. [Medline] [CrossRef]

16) Macedo LG, Latimer J, Maher CG, et al.: Effect of motor control exercises versus graded activity in patients with chronic nonspecific low back pain a randomized controlled trial. Phys Ther, 2012, 92: 363-377. [Medline] [CrossRef]

17) Wang XQ, Zheng JJ, Yu ZW, et al.: A meta-analysis of core stability exercise versus general exercise for chronic low back pain. PLoS ONE, 2012, 7: e52082. [Medline] [CrossRef]

18) Olivier N, Thevenon A, Berthoin $\mathrm{S}$, et al.: An exercise therapy program can increase oxygenation and blood volume of the erector spinae muscle during exercise in chronic low back pain patients. Arch Phys Med Rehabil,
2013, 94: 536-542. [Medline] [CrossRef]

19) Fryer J, Zhang W: Preliminary investigation into a seated unloading movement strategy for the lumbar spine: a pilot study. J Bodyw Mov Ther, 2010, 14: 119-126. [Medline] [CrossRef]

20) Williams R, Binkley J, Bloch R, et al.: Reliability of the modified-modified Schöber and double inclinometer methods for measuring lumbar flexion and extension. Phys Ther, 1993, 73: 33-44. [Medline]

21) Ferreira-Valente MA, Pais-Ribeiro JL, Jensen MP: Validity of four pain intensity rating scales. Pain, 2011, 152: 2399-2404. [Medline] [CrossRef]

22) Aota $Y$, Iizuka $H$, Ishige $Y$, et al.: Effectiveness of a lumbar support continuous passive motion device in the prevention of low back pain during prolonged sitting. Spine, 2007, 32: E674-E677. [Medline] [CrossRef]

23) Grondin DE, Triano JJ, Tran S, et al.: The effect of a lumbar support pillow on lumbar posture and comfort during a prolonged seated task. Chiropr Man Therap, 2013, 21: 21. [Medline] [CrossRef]

24) Kingma I, van Dieën JH: Static and dynamic postural loadings during computer work in females: Sitting on an office chair versus sitting on an exercise ball. Appl Ergon, 2009, 40: 199-205. [Medline] [CrossRef]

25) van Deursen DL, Goossens RH, Evers JJ, et al.: Length of the spine while sitting on a new concept for an office chair. Appl Ergon, 2000, 31: 95-98. [Medline] [CrossRef]

26) Purepong N, Jitvimonrat A, Boonyong S, et al.: Effect of flexibility exercise on lumbar angle: a study among non-specific low back pain patients. J Bodyw Mov Ther, 2012, 16: 236-243. [Medline] [CrossRef]

27) Hongsuwan $\mathrm{C}$, Eungpinichpong $\mathrm{W}$, Chatchawan U, et al.: Effects of Thai massage on physical fitness in soccer players. J Phys Ther Sci, 2015, 27: 505-508. [Medline] [CrossRef]

28) Prommanon B, Puntumetakul R, Puengsuwan P, et al.: Effectiveness of a back care pillow as an adjuvant physical therapy for chronic non-specific low back pain treatment: a randomized controlled trial. J Phys Ther Sci, 2015, 27: 2035-2038. [Medline] [CrossRef]

29) Magnusson SP, Aagard P, Simonsen E, et al.: A biomechanical evaluation of cyclic and static stretch in human skeletal muscle. Int J Sports Med, 1998, 19: 310-316. [Medline] [CrossRef] 